\title{
Effects of Appearance Satisfaction, Self-Esteem, and Interpersonal Relationship Satisfaction in University Students on Employment Stress
}

\author{
Ga-eun Song ${ }^{1}$, Eun-sil Kim ${ }^{2}$, Joo-hyun Shin ${ }^{3}$ \\ ${ }^{1}$ Master, Child Counseling Psychology, Namseoul University Graduate School, Korea, \\ sksmsrkdms@naver.com \\ ${ }^{2}$ Professor, Department of Child Welfare, Namseoul University, Korea, gender@hanmail.net \\ ${ }^{3}$ Ph.D, Addiction Rehabilitation Counseling, Namseoul University Graduate School, Korea, \\ findingflow5@gmail.com
}

Corresponding author: Eun-sil Kim

\begin{abstract}
The purpose of this study was to assess the effects of appearance satisfaction, self-esteem, and interpersonal relationship satisfaction of university students on employment stress. a total of 394 male and female students attending universities in Seoul, Gyeonggi, Cheonan, and Daejeon to the survey questionnaire. Two research questions were established; Research Question 1: Are there differences in appearance satisfaction, self-esteem, interpersonal relationship satisfaction, and employment stress of university students according to demographic characteristics?, Research Question 2: Do appearance satisfaction, self-esteem and interpersonal relationship satisfaction of university students affect employment stress? From the survey, appearance satisfaction, self-esteem, and interpersonal relationship satisfaction were higher on average in the 20-22-year-old group, and employment stress was lower in the 20-22-year-old group than the rest of the age groups. Moreover, appearance satisfaction and interpersonal relationship satisfaction had effects on employment stress in contrast to self-esteem, which did not affect employment stress. Therefore, this study dealt with the employment stress by evaluating the impact of appearance satisfaction, self-esteem and interpersonal satisfaction on college student's employment stress, and aimed to provide basic data on factors that affect employment stress. Despite the meaningfull results, the follow-up studies were suggested as follows. First, this was selfreported questionnaire designed in this study so that the participants were more likely to respond in socially desirable ways. In subsequent studies, the shortcomings of the self-report questionnaire need to be overcome by combining qualitative and quantitative studies. Second, since this study was conducted only on university students in certain areas, it is difficult to generalize the results, and the range of samples and areas needs to be expanded in subsequent studies.
\end{abstract}

Keywords: University Students, Appearance Satisfaction, Self-esteem, Interpersonal Relationship Satisfaction, Employment Stress

\section{Introduction}

University students tend to feel the burden of their grades, career paths, and employment. They are more likely to take career decisions as real-life problems and worry at a serious level, which leads to employment stress (Lee Mi-Kyung,2004)[1]. When the level of stress is severe, this can have negative

Received: September 07, 2020; 1st Review Result: October 29, 2020; 2nd Review Result: December 16, 2020 Accepted: January 25, 2021 
effects such that the individual is unable to achieve emotional, behavioral, and physical harmony (Lee Mi-sook, 2011)[2] and cause psychological, mental disorders (Yu Bong-min, 2011)[3]. As a result, it affects impression formation, appearance satisfaction, and interpersonal relationships (Lee Eun-hye, 2017)[4].

As employment stress increases, the importance of interviews among university students is also increasing, and in university students, making their appearance beautiful has become an essential specification for competency in employment (Yoon Eun-young, 2012)[5]. In previous studies on the effects of appearance satisfaction on employment stress, students who had a positive image of their appearance acted with confidence in school and external environments. On the other hand, those with a negative image of their appearance were intimidated by others and the external environment, which led to loss of their confidence in finding employment and increased employment stress (Kim Sun-joo, Kim Han-hong, 2014)[6].

In addition, the importance of self-esteem has emerged as a buffering factor that relieves employment stress for successful university life and mental health in university students (Kim Hye-jeong, 2014)[7]. It was observed that higher self-esteem led to more proactive response to and less experiences of academic and career-related stress, suggesting that self-esteem can affect employment stress (Lim Yeonkyung, 2017)[8].

Another important factor that can affect employment stress is interpersonal relationship satisfaction. Higher interpersonal relationship skills lead to increased ability to solve problems through creative and logical thinking (Son Kyung-sook, 2017)[9]. It also has positive effects on satisfaction in university life and major (Shim Sun-sook, Bang Mi-ran, 2016)[10], in addition to improving basic vocational skills (Lee Jae-han, Lim Sang-ho, 2017)[11]. Although these are important variables for employment stress in university students, only few studies have assessed the effects of appearance satisfaction, self-esteem, and interpersonal relationship satisfaction on employment stress.

Therefore, this study aimed to evaluate whether appearance satisfaction, self-esteem, and interpersonal relationship satisfaction have effects on employment stress in university students in order to help university students effectively cope with job stress and provide basic data on factors that influence job stress.

\section{Contents}

\subsection{Research Subjects}

The subjects in this study were a total of 394 male and female university students in their 1st to 5th year, attending universities in Seoul, Gyeonggi, Cheonan, and Daejeon.

\subsection{Research Tools}

\subsubsection{Appearance Satisfaction Scale}

In this study, the Body Esteem Scale (BES) developed by, modified by, and used by Franzoi (1984), Cho Min-kyung (2014)[12], and Lim Mi-ji (2018)[13], respectively, was used to evaluate appearance satisfaction. The overall reliability of this test tool was .918 .

\subsubsection{Self-Esteem Scale}

In this study, the Self-Esteem Scale developed by Rosenberg (1965) was used to assess self-esteem, and this scale consisted of 5 items each for positive self-esteem and negative self-esteem. The overall reliability of this test tool was .880 . 


\subsubsection{Interpersonal Relationship Satisfaction Scale}

The interpersonal relationship scale that was modified by Moon Sun-mo (1980) from the relationship change scale of Guerney (1997) was used to measure interpersonal relationships. This scale consisted of 25 questions in total, including $7 \mathrm{sub}$ areas of satisfaction, communication, trust, friendliness, sensitivity, openness, and understanding. The overall reliability in this study was .966 .

\subsubsection{Employment Stress Scale}

To assess employment stress, the Cornell Medical Index (CMI), developed by, modified and revised by, and used by Cornell University, Hwang Sung-won (1988) and Kang Yu-ri (2006)[14], and Hwang Myung-joo (2019)[15] was used in this study. The employment stress scale consisted of 22 questions in total and is composed of sub factors including personality stress, academic stress, family environment stress, school environment stress, and employment anxiety stress. The overall reliability in this study was .928.

\subsection{Research Procedures}

In this study, offline and online surveys were conducted on 1st-5th year university students enrolled in universities in Seoul, Gyeonggi, Cheonan, and Daejeon, who agreed to participate in the research after receiving an explanation about the research objectives. A total of 431 students participated in the survey, of which 394 data were analyzed, excluding 37 students who did not answer properly or withdrew during the survey.

\section{Results}

3.1 Differences in Appearance Satisfaction, Self-esteem, Interpersonal Relationship Satisfaction, and Employment Stress according to Demographic Characteristics of University Students

\subsubsection{Differences in Appearance Satisfaction, Self-esteem, Interpersonal Satisfaction, and Employment Stress according to Gender}

[Table 1] Differences in Appearance Satisfaction, Self-esteem, Interpersonal Satisfaction, and Employment Stress according to Gender

\begin{tabular}{cccccc}
\hline \multirow{2}{*}{ Factor } & \multicolumn{2}{c}{ Men(N=166) } & \multicolumn{2}{c}{ Women(N=190) } & $\mathrm{t}$ \\
\cline { 2 - 5 } & $M$ & $S D$ & 3.51 & 0.86 & .278 \\
\hline \hline Appearance satisfaction & 3.54 & 0.83 & 4.02 & 0.77 & .141 \\
\hline Self-esteem & 4.03 & 0.75 & 3.83 & 0.74 & -.288 \\
\hline $\begin{array}{c}\text { Interpersonal relationship } \\
\text { satisfaction }\end{array}$ & 3.80 & 0.71 & & & \\
\hline Employment stress & 2.36 & 1.09 & 2.36 & 1.08 & .037 \\
\hline
\end{tabular}

T-test showed that the differences in appearance satisfaction $(\mathrm{t}=.278, \mathrm{p}>.05)$, self-esteem $(\mathrm{t}=.141$, $\mathrm{p}>.05)$, interpersonal relationship satisfaction $(\mathrm{t}=-.288, \mathrm{p}>.05)$, and employment stress $(\mathrm{t}=.037, \mathrm{p}>.05)$ according to gender were not statistically significant [Table 1]. 
3.1.2 Differences in Appearance Satisfaction, Self-esteem, Interpersonal Relationship Satisfaction, and Employment Stress according to Age

[Table 2] Differences in Appearance Satisfaction, Self-esteem, Interpersonal Relationship Satisfaction, and Employment Stress according to Age

\begin{tabular}{|c|c|c|c|c|c|c|}
\hline Factor & Age & $N$ & $M$ & $S D$ & $F$ & Post-hoc test \\
\hline \multirow{4}{*}{$\begin{array}{l}\text { Appearance } \\
\text { satisfaction }\end{array}$} & 20-22-year-old a & 165 & 3.82 & 0.69 & \multirow{4}{*}{$21.07^{* * * *}$} & \multirow{4}{*}{$a>b, c$} \\
\hline & 23-25-year-old b & 127 & 3.31 & 0.90 & & \\
\hline & 26-year-old or above c & 64 & 3.20 & 0.84 & & \\
\hline & Total & 356 & 3.52 & 0.84 & & \\
\hline \multirow{4}{*}{ Self-esteem } & 20-22-year-old a & 165 & 4.31 & 0.64 & \multirow{4}{*}{$24.52^{* * *}$} & \multirow{4}{*}{$a>b, c$} \\
\hline & 23-25-year-old b & 127 & 3.78 & 0.77 & & \\
\hline & 26-year-old or above c & 64 & 3.78 & 0.76 & & \\
\hline & Total & 356 & 4.03 & 0.76 & & \\
\hline \multirow{4}{*}{$\begin{array}{l}\text { Interpersonal } \\
\text { relationship } \\
\text { satisfaction }\end{array}$} & 20-22-year-old a & 165 & 4.09 & 0.64 & \multirow{4}{*}{$26.09^{* * *}$} & \multirow{4}{*}{$a>b, c$} \\
\hline & 23-25-year-old b & 127 & 3.61 & 0.70 & & \\
\hline & 26-year-old or above c & 64 & 3.51 & 0.72 & & \\
\hline & Total & 356 & 3.82 & 0.73 & & \\
\hline \multirow{4}{*}{$\begin{array}{c}\text { Employment } \\
\text { stress }\end{array}$} & 20-22-year-old a & 165 & 1.70 & 0.76 & \multirow{4}{*}{$80.56^{* * *}$} & \multirow{4}{*}{$\mathrm{a}<\mathrm{b}, \mathrm{c}$} \\
\hline & 23-25-year-old b & 127 & 2.90 & 1.07 & & \\
\hline & 26-year-old or above c & 64 & 2.96 & 0.87 & & \\
\hline & Total & 356 & 2.36 & 1.09 & & \\
\hline
\end{tabular}

One-way ANOVA showed that statistically significant differences were observed in appearance satisfaction $(\mathrm{F}=21.07, \mathrm{p}<.001)$, self-esteem $(\mathrm{F}=24.52, \mathrm{p}<. .001)$, interpersonal relationship satisfaction $(\mathrm{F}=26.09, \mathrm{p}<.001)$, and employment stress $(\mathrm{F}=80.56, \mathrm{p}<.001)$ according to age.

\subsubsection{Differences in Appearance Satisfaction, Self-esteem, Interpersonal Satisfaction, and Employment Stress by Region}

[Table 3] Differences in Appearance Satisfaction, Self-esteem, Interpersonal Satisfaction, and Employment Stress by Region

\begin{tabular}{ccccccc}
\hline Factor & Region & $N$ & $M$ & $S D$ & $F$ & Post-hoc test \\
\hline \hline & Gyeonggi $^{\mathrm{a}}$ & 104 & 3.40 & 0.86 & & \\
Appearance & Cheonan $^{\mathrm{b}}$ & 92 & 3.44 & 0.97 & 2.504 & a,b,c,d \\
satisfaction & Seoul $^{\mathrm{c}}$ & 88 & 3.63 & 0.72 & & \\
& Daejeon & & & & \\
& 72 & 3.68 & & \\
\end{tabular}




\begin{tabular}{|c|c|c|c|c|c|c|}
\hline & & & & & & \\
\hline & Total & 356 & 3.52 & 0.84 & & \\
\hline \multirow{5}{*}{ Self-esteem } & Gyeonggi $^{a}$ & 104 & 3.77 & 0.81 & \multirow{5}{*}{$6.865^{\star * \star}$} & \multirow{5}{*}{$\mathrm{a}<\mathrm{c}, \mathrm{d}$} \\
\hline & Cheonan ${ }^{\mathrm{b}}$ & 92 & 4.02 & 0.78 & & \\
\hline & Seoul $^{\mathrm{c}}$ & 88 & 4.19 & 0.63 & & \\
\hline & Daejeon $^{\mathrm{d}}$ & 72 & 4.19 & 0.69 & & \\
\hline & Total & 356 & 4.03 & 0.76 & & \\
\hline \multirow{5}{*}{$\begin{array}{l}\text { Interpersonal relationship } \\
\text { satisfaction }\end{array}$} & Gyeonggi $^{\mathrm{a}}$ & 104 & 3.64 & 0.70 & \multirow{5}{*}{$3.229^{*}$} & \multirow{5}{*}{$a<d$} \\
\hline & Cheonan $^{\mathrm{b}}$ & 92 & 3.84 & 0.80 & & \\
\hline & Seoul $^{\mathrm{c}}$ & 88 & 3.89 & 0.70 & & \\
\hline & Daejeon $^{\mathrm{d}}$ & 72 & 3.95 & 0.65 & & \\
\hline & Total & 356 & 3.82 & 0.73 & & \\
\hline \multirow{5}{*}{ Employment stress } & Gyeonggi $^{a}$ & 104 & 2.70 & 1.17 & \multirow{5}{*}{$8.294^{\star \star \star}$} & \multirow{5}{*}{$a<b, c<d$} \\
\hline & Cheonan ${ }^{\mathrm{b}}$ & 92 & 2.45 & 1.11 & & \\
\hline & Seoul $^{\mathrm{c}}$ & 88 & 2.18 & 0.98 & & \\
\hline & Daejeon $^{\mathrm{d}}$ & 72 & 1.95 & 0.88 & & \\
\hline & Total & 356 & 2.36 & 1.09 & & \\
\hline
\end{tabular}

One-way ANOVA showed that there were no statistically significant differences in appearance satisfaction by region $(\mathrm{F}=2.504, \mathrm{p}>.05)$. However, self-esteem $(\mathrm{F}=6.865, \mathrm{p}<.001)$, interpersonal relationship satisfaction $(\mathrm{F}=3.229, \mathrm{p}<.05)$, and employment stress $(\mathrm{F}=8.294, \mathrm{p}<.001)$ were all significantly different according to region.

3.1.4 Differences in Appearance Satisfaction, Self-esteem, Interpersonal Relationship Satisfaction, and Employment Stress according Major

[Table 4] Differences in Appearance Satisfaction, Self-esteem, Interpersonal Relationship Satisfaction, and Employment Stress according Major

\begin{tabular}{|c|c|c|c|c|c|c|}
\hline Factor & Major & $N$ & $M$ & $S D$ & $F$ & Post-hoc test \\
\hline \multirow[t]{6}{*}{ Appearance satisfaction } & Health welfare a & 93 & 3.59 & 0.80 & .786 & $\mathrm{a}, \mathrm{b}, \mathrm{c}, \mathrm{d}$ \\
\hline & $\begin{array}{c}\text { Humanities and social } \\
\text { sciences b }\end{array}$ & 63 & 3.47 & 0.88 & $=$ & \\
\hline & Business c & 35 & 3.32 & 0.84 & & \\
\hline & Natural engineering $d$ & 67 & 3.57 & 0.84 & & \\
\hline & Arte & 98 & 3.54 & 0.86 & & \\
\hline & Total & 356 & 3.52 & 0.84 & & \\
\hline
\end{tabular}




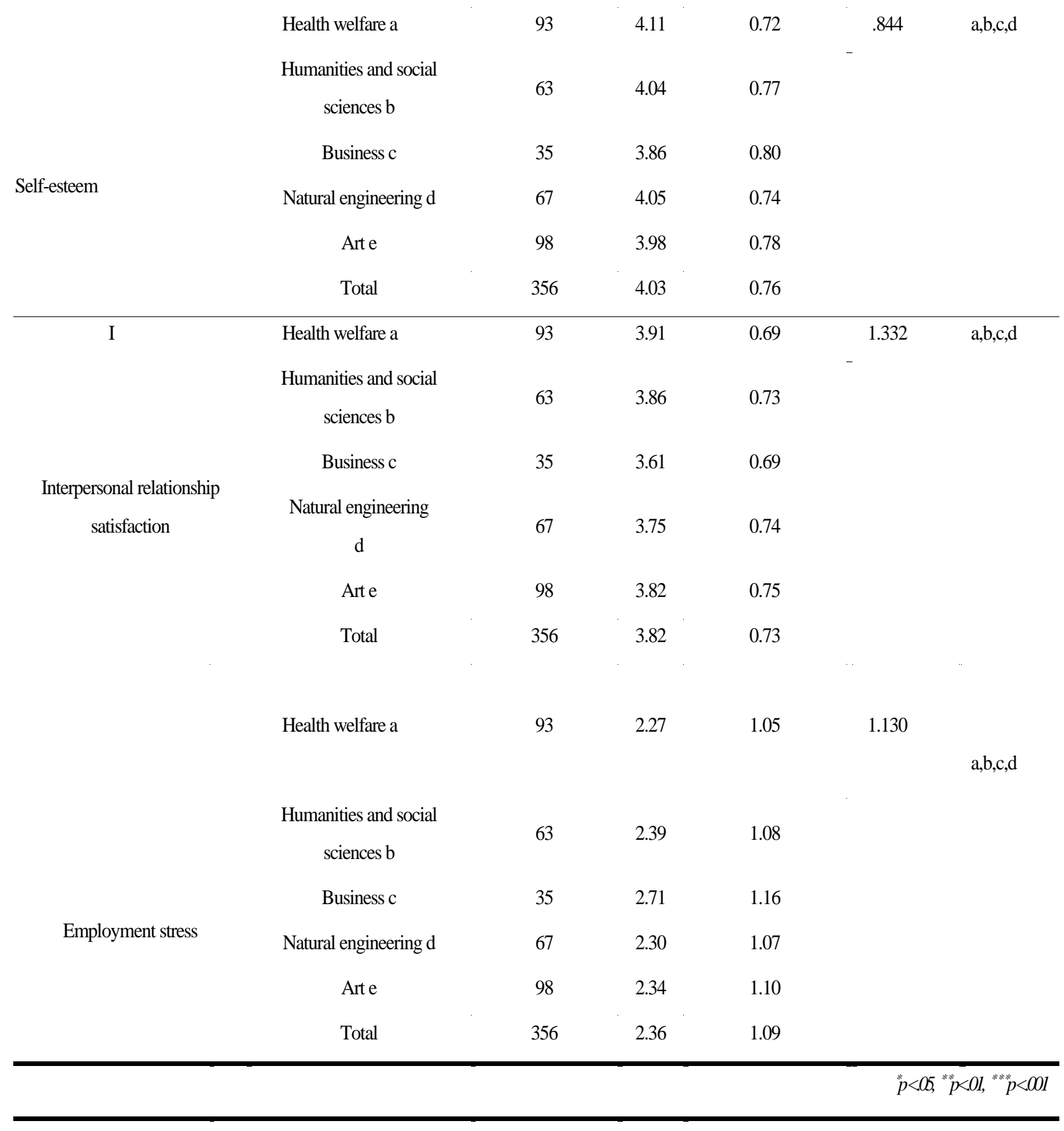

As illustrated in [Table 4], there were no statistically significant differences in appearance satisfaction $(\mathrm{F}=.786, \mathrm{p}>.05)$, self-esteem $(\mathrm{F}=.844, \mathrm{p}>.05)$, interpersonal relationship satisfaction $(\mathrm{F}=1.332, \mathrm{p}>.05)$, and employment stress $(\mathrm{F}=.1 .130, \mathrm{p}>.05)$ according to major.

\subsection{Effects of Appearance Satisfaction, Self-esteem, and Interpersonal Satisfaction on Employment} Stress

The Pearson correlation coefficient was measured to assess the correlation between appearance satisfaction, self-esteem, interpersonal satisfaction, and employment stress, and the results are shown in [Table 5]. 
3.2.1 Correlation between Appearance Satisfaction, Self-esteem, Interpersonal Satisfaction, and Employment Stress

[Table 5] Correlation between Appearance Satisfaction, Self-esteem, Interpersonal Satisfaction, and Employment Stress

\begin{tabular}{|c|c|c|c|c|}
\hline & $\begin{array}{l}\text { Appearance } \\
\text { satisfaction }\end{array}$ & Self-esteem & $\begin{array}{c}\text { Interpersonal } \\
\text { relationship } \\
\text { satisfaction }\end{array}$ & Employment s tress \\
\hline Appearance satisfaction & 1 & & & \\
\hline Self-esteem & $.914^{* * *}$ & 1 & & \\
\hline $\begin{array}{l}\text { Interpersonal relationship } \\
\text { satisfaction }\end{array}$ & $.878^{* * *}$ & $.905^{* * *}$ & 1 & \\
\hline Employment s tress & $-.662^{* * *}$ & $-.657^{* * *}$ & $-.646^{* * *}$ & 1 \\
\hline
\end{tabular}

As a result of assessing the correlation between appearance satisfaction, self-esteem, interpersonal satisfaction and employment stress, employment stress showed statistically significant negative correlations with appearance satisfaction $(\mathrm{r}=-.662, \mathrm{p}<.001)$, self-esteem $(\mathrm{r}=-.657, \mathrm{p}<.001)$, and interpersonal relationship satisfaction $(\mathrm{r}=-.646, \mathrm{p}<.001)$. In other factors, appearance satisfaction and self-esteem $(\mathrm{r}=.914, \mathrm{p}<.001)$, appearance satisfaction and interpersonal relationship satisfaction $(\mathrm{r}=.878$, $\mathrm{p}<.001)$, interpersonal relationship satisfaction and self-esteem $(\mathrm{r}=.905, \mathrm{p}<.001)$ showed positive correlations.

\subsubsection{Effects of Appearance Satisfaction, Self-esteem, and Interpersonal Satisfaction on Employment Stress}

Analysis of the effects of appearance satisfaction and interpersonal relationship satisfaction on employment stress showed that appearance satisfaction $(\beta=-.406, p<.001)$ had statistically significant negative effects on employment stress. In addition, interpersonal relationship satisfaction $(\beta=-.296$, $\mathrm{p}<.001)$ was observed to have statistically significant negative effects on employment stress. However, self-esteem factor was insignificant at a significance level of 5\%.

[Table 6] Effects on employment stress

\begin{tabular}{|c|c|c|c|c|c|c|c|c|c|}
\hline Independent variable & $B$ & $S E$ & Beta & $t$ & $p$ & $V I F$ & $D W$ & $R^{2}$ & $F$ \\
\hline (Constant) & 6.017 & .250 & & 24.028 & .000 & & & & \\
\hline Appearance satisfaction & -.406 & .130 & -.315 & -3.119 & .002 & 6.655 & & & $100.261^{* * *}$ \\
\hline $\begin{array}{l}\text { Interpersonal relationship } \\
\text { satisfaction }\end{array}$ & -.296 & .144 & -.198 & -2.057 & .040 & 6.031 & 1.879 & .461 & $(.000)$ \\
\hline Self-esteem & -.272 & .163 & -.190 & -1.673 & .095 & 8.405 & & & \\
\hline
\end{tabular}




\section{Conclusions}

The purpose of this study was to assess the effects of appearance satisfaction, self-esteem, and interpersonal satisfaction on employment stress in university students. Discussion on the results of this study is as follows.

First, the differences in appearance satisfaction, self-esteem, interpersonal relationship satisfaction, and employment stress among university students according to demographic characteristics were assessed. As a result, appearance satisfaction of university students was higher on average in the 20-22year-old group, and there were no significant differences in gender, region, and major. self-esteem was higher on average in the 20-22-year-old group than the rest of the age groups, and the average selfesteem in Seoul and Daejeon were higher than that in Gyeonggi. In contrast, there were no significant differences in gender and major.

In addition, Interpersonal relationship satisfaction was higher on average in the 20-22-year-old group than the rest of the age groups. Moreover, interpersonal relationship satisfaction was higher in Daejeon than the Gyeonggi on average. On the other hand, there were no significant differences in gender and major.

Employment stress in the 20-22-year-old group was lower than that of the rest of the age groups, and on average, employment stress in Cheonan and Seoul was higher and lower than that in Gyeonggi and that in Daejeon, respectively. On the other hand, there were no significant differences in gender and major.

Second, the effects of appearance satisfaction, self-esteem, and interpersonal relationship satisfaction of university students on employment stress were assessed. As a result, it was observed that appearance satisfaction and interpersonal satisfaction were variables affecting employment stress. These results indicate that depression and employment stress are lower in those with higher appearance satisfaction (Lee In-sook, 2011)[16]. Furthermore, similar to studies which reported that an individual is more likely to succeed in society if the individual has good interpersonal relationships (Kwon Bo-yeon, 2000)[17] and that employment stress decreases with increased interpersonal relationship satisfaction (Kim Jeonghyun, 2016)[18], it can be seen that increasing appearance satisfaction and interpersonal relationship satisfaction has important effects in reducing employment stress.

On the other hand, self-esteem was a variable that did not affect employment stress. This result is not consistent with previous studies which reported that the higher self-esteem , the lower the employment stress (Kim Jeong-hyun, 2016)[18] and that self-esteem of university students is closely related to employment stress (Kang Kyung-hoon, 2010)[19]. Moreover, in a study by Lee Hyun-jung (2012)[20] that assessed employment stress and self-esteem in university students, it was reported that there was no difference in PPAT, a picture test that can evaluate the level of employment stress, between university students with and without high self-esteem. In addition, it was found that the level of self-esteem was not related to logic, energy, and problem-solving ability related to employment.

This study is meaningful in that it has comprehensively assessed how appearance satisfaction, interpersonal relationship satisfaction, and self-esteem affect employment stress. However, the research method is the limitation of this study, both self-report questionnaire and smaple size and based on this, follow-up studies are suggested as follows.

First, the questionnaire conducted in this study was a self-report questionnaire. Thus, it is possible that the participants responded in socially desirable ways. In subsequent studies, the shortcomings of the self-report questionnaire need to be overcome by combining qualitative and quantitative studies.

Second, since this study was conducted only on university students in certain areas, it is difficult to generalize the results, and the range of samples and areas needs to be expanded in subsequent studies. 


\section{References}

[1] Mi-Kyung Lee, A Study on the Employment Stress and Career Self-Efficacy of University Students: Focusing on Jeollabuk-do, Hanil Jangshin University, Master's thesis, (2004)

[2] Mi-sook Lee, A Study on the Employment Stress Scale, Kyungpook National University, Master's thesis, (2011)

[3] Bong-min Yu, The relationship between employment stress, career attitude maturity, and mental health: focusing on university students in health and non-health fields, Ajou University, Master's thesis, (2011)

[4] Eun-hye Lee, A Study on the Effect of College Students' Appearance Satisfaction, Self-efficacy and Interpersonal Relationship Satisfaction and Interpersonal Relationship Satisfaction, Seoul Hanyoung University, Master's thesis, (2017)

[5] Eun-young Yoon, Differences in achievement motivation and interpersonal relationships according to appearance satisfaction in university students, Chungnam National University, Master's thesis, (2012)

[6] Sun-joo Kim, Han-hong Kim, Impact of appearance satisfaction and ego-resilience on employment stress among dental hygiene students, Journal of Korean Society of Dental Hygiene, (2014), Vol.14, No.1, pp.75-84, DOI : $10.13065 / \mathrm{jksdh} .2014 .14 .01 .75$

[7] Hye-jeong Kim, The Effect of College Students' Attach to Parents, Caveer Maturity and Self-Esteem on Employment Stress Doctoral dissertation, Daegu Haany University, Master's thesis, (2014)

[8] Yeon-kyung Lim, Impacts of Appearance Satisfaction, Self-esteem, And Career-choice Readiness on Job-Seeking Stress of College Students Majoring in Airline Service, Sejong University Graduate School of Industry, Master's thesis, (2017)

[9] Taekyung Park, Program development and effectiveness verification to promote self-realization of middle-aged women, Daegu University, Doctor dissertation, (2019)

[10] Sun-sook Shim, Mi-ran Bang, The relationship between the character, interpersonal relations, and adjustment to a college life of nursing students, Journal of the Korea Academia-Industrial cooperation Society, (2016), Vol.17, No.12, pp.634-642, DOI : 10.5762/KAIS.2016.17.12.634

[11] Jae-han Lee, Sang-ho Lim, The Effect of Interpersonal Relations Ability of College Students on Basic Skills, Industry Promotion Research, (2017), Vol.2, No.1, pp.51-56.

[12] Min-kyung Cho, Mediation of Interpersonal Relationship Experience in the Relationship between Appearance Satisfaction and Self-Esteem of High School Students, Myongi University, Master's Thesis, (2014)

[13] Mi-ji Lim, Analysis of the Structural Relationships among Appearance Satisfaction, Rejection Sensitivity, Social Support, Ego-Resilience and Psychological Well-Being of High School Students, Dong-A University, Master's thesis, (2018)

[14] Yu-ri Kang, Dance of the major college career maturity, the impact on job stress, Dankook University, Master's thesis, (2006)

[15] Myung-joo Hwang, The Effect of Job Search Stress of College Students on Mental Health and Suicide Behavior Mediating Effect of Ego Resilience-, Widuk University Graduate School, Master's Thesis, (2019)

[16] In-suk Lee, A Study on the Employment Stress Scale, Kyungpook National University, Master's thesis, (2011)

[17] Bo-yeon Kwon, A Study on relations of First year college student's Type of Interpersonal relationship Problems and their perceived Parent-Child Communication Style and Child Rearing Style, Yonsei University, Master's thesis, (2000)

[18] Jeong-hyun Kim, Differences in interpersonal relationship competence and achievement motivation according to the level of self-identity in real and virtual spaces, Chosun University, Master's Thesis, (2016)

[19] Kyung-hoon Kang, A study on relationships among college students`self-differentiation, self-esteem and employment stress, Inje University, Master's thesis, (2010) 
Effects of Appearance Satisfaction, Self-Esteem, and Interpersonal Relationship Satisfaction in University Students on Employment Stress

[20] Lee Hyun-jung, The Characteristics of Responses to PPAT(Person Picking an Apple from a Tree) Assessment on the Level of Employment Stress and Self-Esteem of University Students, Seoul Women's National Graduate School of Special Therapy, Master's Thesis, (2012) 